\title{
Women mentoring women
}

Carolyn Chang, MD, ${ }^{\mathrm{a}}$ Tessa M. F. Watt, MD, ${ }^{\mathrm{b}}$ Amy G. Fiedler, MD, ${ }^{\mathrm{c}}$ and Stephanie G. Worrell, $\mathrm{MD}^{\mathrm{d}}$

The year 2017 was monumental for women in medicine. For the first time in history, women comprised more than $50 \%$ of medical school matriculates and $41 \%$ of general surgery residents. ${ }^{1}$ Women also made enormous strides in national surgical leadership. Dr Leigh Neumayer became the first female chair of the American College of Surgeons Board of Regents and Dr Diane Farmer became the first female chair of the American College of Surgeons Board of Governors. ${ }^{2}$ Until 1970 , women made up only $6 \%$ of any medical school class and $2 \%$ of all surgical residents in the United States. ${ }^{3}$ Currently, 24 women are chairs of departments of surgery at academic institutions across the United States (https://www.womensurgeons.org/page/ FemaleSurgeryChairs), including Cardiothoracic surgeon, Dr Christine Lau. ${ }^{2}$ Although the gender gap is narrowing, this is not true across all surgical subspecialties.

The field of cardiothoracic surgery remains maledominated, with only $20 \%$ of cardiothoracic surgery residents and 5\% of American Board of Thoracic Surgery (ABTS)-boarded surgeons being female in $2017 .{ }^{4}$ The reasons for this are multifactorial and deeply rooted within the gender inequities that still exist. Most recently, The Society of Thoracic Surgeons (STS) Workforce on Diversity and Inclusion published a framework to address diversity and inclusion within cardiothoracic surgery. It outlines that efforts will require a series of concentric spheres of influence from the global environment to the cardiothoracic community, institution, and the individual surgeon. ${ }^{5}$ Our goal is to touch on just 1 component that we believe can make a tremendous difference in supporting women's success in cardiothoracic surgery careers. This article highlights the history of women in cardiothoracic surgery and the current and future roles of mentorship, sponsorship, and promotion.

\footnotetext{
From the ${ }^{a}$ Department of Surgery, Oregon Health and Sciences University, Portland, Ore; ${ }^{b}$ Department of Cardiac Surgery, University of Michigan, Ann Arbor, Mich; ${ }^{\mathrm{c}}$ Division of Cardiothoracic Surgery, Department of Surgery, University of Wisconsin, Madison, Wis; and ${ }^{\mathrm{d}}$ Division of Thoracic and Esophageal Surgery, Department of Surgery, University Hospitals Cleveland Medical Center, Cleveland, Ohio. Disclosures: The authors reported no conflicts of interest.

The Journal policy requires editors and reviewers to disclose conflicts of interest and to decline handling or reviewing manuscripts for which they may have a conflict of interest. The editors and reviewers of this article have no conflicts of interest.

Received for publication May 31, 2021; revisions received Oct 8, 2021; accepted for publication Oct 19, 2021; available ahead of print Nov 4, 2021.

Address for reprints: Stephanie G. Worrell, MD, Department of Surgery, 11100 Euclid Ave, Lakeside 7th Fl, Suite 7550, Cleveland, OH 44016-5047 (E-mail: stephanie.worrell@UHhospitals.org).

J Thorac Cardiovasc Surg 2023;165:401-5

0022-5223/\$36.00

Copyright (c) 2021 by The American Association for Thoracic Surgery

https://doi.org/10.1016/j.jtcvs.2021.10.053
}

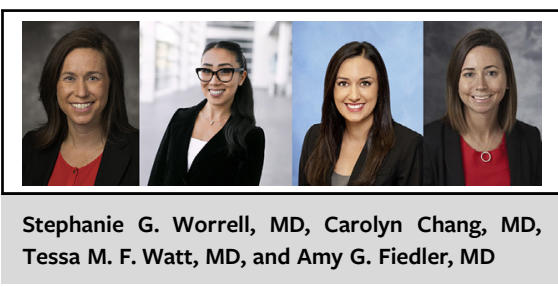

CENTRAL MESSAGE

A next step toward achieving a

true seat at the table includes mentorship and visibility. Watching and learning from senior women who have succeeded will only help future generations succeed.

\begin{abstract}
PERSPECTIVE
The field of cardiothoracic surgery remains maledominated, with only $20 \%$ of cardiothoracic surgery residents and $5 \%$ of American Board of Thoracic Surgery-certified surgeons being female in 2017. This article highlights the history of women in cardiothoracic surgery and the current and future roles of mentorship, sponsorship, and promotion.
\end{abstract}

See Commentary on page 406.

\section{HISTORICAL PERSPECTIVE}

Women have been performing surgery since the early 1800s. The "beardless lad" was an army surgeon known as Dr James Barry, who performed surgery during the Napoleonic wars. Dr Barry concealed her sex throughout the duration of her practice and was found to be female after her death in 1865 . $^{6}$ The American College of Surgeons admitted its first female member in 1913 and 5 or fewer women each year thereafter, until $1975 .{ }^{4}$ Even in the advent of modern surgical training, brought by Halstead, this road has proven difficult for women.

The history of the modern era of thoracic surgery began with the first organizational meeting of the ABTS held in the United States in $1948 .{ }^{8}$ In 1961, 12 years after the first ABTS examination, Nina Starr Braunwald, Ann McKiel, and Nermin Tuttunji became the first 3 women to be board-certified by the ABTS. ${ }^{6}$ Nina Starr Braunwald was a pioneer who earned many accolades for her extraordinary 
accomplishments, despite the overwhelming obstacles of gender discrimination. On March 11, 1960, in a "surgical first," she successfully replaced the diseased mitral valve of a 44-year-old woman with severe rheumatic mitral regurgitation. ${ }^{9}$ During her time at the University of California in San Diego, she established an open-heart surgery program and performed the first coronary bypass in the San Diego area. Later, she became the first woman surgical faculty member at Harvard.

Despite these firsts, there was very little change in the gender demographic of thoracic surgery, with only 10 additional women becoming board-certified by $1980 .{ }^{7}$ Dr Leslie Kohman, an academic general thoracic surgeon, was one of those 10 women and was instrumental in building the early community of women cardiothoracic surgeons. ${ }^{10}$ With only 10 women, few introductions were needed as friendships and camaraderie naturally developed at national meetings. Dr Kohman took it one step further and invited any women surgeons she encountered to informal breakfast meetings at the STS and American Association for Thoracic Surgery meetings. These women met every year to hear news, socialize, and network-activities especially important in breaking barriers of distance, training, and practice commitments. ${ }^{11}$ These organized meetings later became the organization that is now Women in Thoracic Surgery (WTS) in 1986, which has helped to shape the US experience for women in thoracic surgery. ${ }^{4}$

In 1988, the first Women in Cardiothoracic Surgery Newsletter was sent to 30 women surgeons with particular focus on using this platform to foster a women's professional group interested in career development. Early goals included promoting networking and access to information about residencies, faculty positions, and research and clinical opportunities and to interact with other groups of professional women. ${ }^{11}$ By the end of the decade, WTS had 84 members in private, group, and academic surgical practices across the United States. The society matured and developed a clear mission to enhance the quality of medical care given to patients of its members, to mentor young women thoracic surgeons, to enhance the education of patients about cardiac and thoracic pathologies, and to enhance educational opportunities for women thoracic surgeons. ${ }^{10}$

With the number of women cardiothoracic surgeons steadily increasing, a survey that compared female cardiothoracic surgeons with a matched group of male surgeons was completed in $1993 .{ }^{4}$ The most striking finding was that $45 \%$ of male respondents would not encourage women toward a career in surgery. ${ }^{12}$ This highlighted the compelling need for female cardiothoracic surgical mentors and role models. The first woman in cardiothoracic surgery recognized for mentoring other women was Dr Carolyn E. Reed. She was the first woman elected to the ABTS and served as chair in 2005. She held several leadership roles within the STS and served as the first woman president of the Southern Thoracic Surgical Association in 2007. ${ }^{13} \mathrm{Dr}$ Reed was a widely renowned surgical educator who "had a unique blend that made life fun yet was a world expert at communicating and improving the education of all of us," said colleague Robert Cerfolio. ${ }^{13}$ She served as the mentor and advisor for numerous medical students, residents, and women faculty members across the United States. It was rare for a week to go by without her receiving at least 1 phone call from a former resident asking her advice about a "tough" case. ${ }^{14}$ At the January 2013 meeting of the STS, she was posthumously awarded the Socrates Award by the Thoracic Surgery Residents Association in recognition of her many contributions to thoracic surgery education and elected the first woman president of the STS. ${ }^{14}$

A history of cardiothoracic leadership would not be thorough without mentioning Dr Rusch and Dr Carpenter. Dr Valerie Rusch has recently served as the president of the American College of Surgeons and has mentored many men and women in cardiothoracic surgery. Dr Andrea J. Carpenter, Professor of Surgery at the University of Texas, Health Science Center at San Antonio, was the fifth president of the WTS and 63rd president of the Southern Thoracic Surgical Association. To honor her achievements, the WTS established the WTS Carpenter Scholarship to fund a female medical student, general surgery resident, or cardiothoracic surgery resident to attend the annual meeting and be mentored at the event. ${ }^{15}$ In addition, more and more women are serving in important leadership roles including Dr Yolonda Colson and Dr Jennifer Lawton. Dr Yolonda Colson, Professor of Surgery and Chief, Division of Thoracic Surgery, will be the first female president of the American Association for Thoracic Surgery. Dr Jennifer Lawton is Professor of Surgery, and Chief, Division of Cardiac Surgery at Johns Hopkins, as well as the Director of the Cardiac Surgery Research Laboratory. ${ }^{15}$

\section{WHERE WE ARE}

Had women been encouraged earlier to pursue cardiothoracic surgery and equally been accepted into leadership roles, the gender discrepancies might be less evident. Cardiothoracic surgeon Virginia Litle, MD, Chief of Thoracic Surgery at Boston Medical Center, suspects that the slow rate of change in the specialty is largely attributable to the training duration, and certain practice realities that don't lend themselves easily to other priorities women might have such as having a family in the more traditional sense. Prospective cardiothoracic surgery trainees are rarely told that it is possible to have an impactful career and achieve work-life balance. ${ }^{15}$ "There has been this perception that cardiothoracic surgery is not for women because it's too intense, and it's a difficult lifestyle," said Dr Litle. ${ }^{16}$ 
This perception places the unequal discrepancy on women and does not address the true underlying cause. In a survey conducted in 2018, male surgeons were significantly less likely than female surgeons to recommend surgery to a female medical student, whereas no difference was reported for male medical students. ${ }^{15}$ However, research shows that men and women describe with equal frequency having made career tradeoffs for personal and family time. ${ }^{17}$

This field involves a long and arduous career path for men and women and the messaging needs to shift. More often, women are dissuaded rather than encouraged to pursue a career in cardiothoracic surgery by peers, partners, and family. ${ }^{18} \mathrm{~A}$ woman from our survey recalled "During one case, I was performing a particular technique inaccurately, and rather than receiving instruction on how to do it right, I was asked, "Are you sure you want to be a cardiothoracic surgeon? Because I can sign you up for nursing school."' Despite research showing that female surgeons perform equally as well as their male counterparts on measures of medical knowledge, communication skills, professionalism technical skills, practice-based learning, and clinical judgement, women still face gendered perceptions. ${ }^{17}$ It is important to note that there are excellent male thoracic surgeons who have been and are willing to provide unparalleled mentorship for women and men.

\section{MENTORSHIP}

Mentorship is a powerful tool and will continue to play a critical role in the rise of women within cardiothoracic surgery. Mentoring is defined as a one-to-one relationship in which an expert or a senior person voluntarily gives time to teach, support, and encourage another. ${ }^{19}$ Mentors serve as a career model, offer advice to help others along the trajectory of their career, and help in navigating difficult situations. This role is extremely important because studies have shown that factors that have a selectively greater effect on women's choice of a surgical career include being at an institution with a higher percentage of female surgical faculty and having a positive perception of career satisfaction of female surgeons. Female medical students who do not meet a same-sex role model during their clerkship are less likely to choose a surgical career. ${ }^{20}$ Men and women report career content as a reason for being satisfied with their surgical careers, and they do so with equal frequency. Of the reasons for dissatisfaction with work, a higher percentage of women's responses named lack of credit and lack of support. ${ }^{17}$ When describing strategies used in developing a successful surgical career, men and women emphasized different things; men gave reasons related to training and compensation and women far more frequently cited social networks as key to success, particularly mentors. ${ }^{17}$ Therefore, limited access to senior women in the field can hamper progress. $^{21}$

\section{SURVEY OF FEMALE MENTORSHIP IN CARDIOTHORACIC SURGERY}

To explore the experience and effect of mentorship in early-career cardiothoracic women, we conducted a prospective survey-based study using surveymonkey.com to anonymously survey women cardiothoracic surgeons who have been in practice for 1 to 4 years (Tables 1 and 2). The University Hospitals Cleveland Medical Center institutional review board approved this study (study 20201229). Email addresses were collected from the Cardiothoracic Surgery Network.

The survey was first sent out on October 23, 2020. To increase our response rate, we sent reminder emails every 2 weeks for a total duration of 6 weeks. There were 27 responders $(41 \%)$ of the 66 contacted. Twelve $(46.2 \%)$ identified as general thoracic surgeons, $11(42.3 \%)$ adult cardiac, $3(11.5 \%)$ congenital, $3(11.55 \%)$ mixed practice, and $1(3.9 \%)$ as other (question skipped by 1 responder). Most women in this study practice in an academic setting $(59.3 \%), 26 \%$ private practice, and $18.5 \%$ in a mixed practice.

The female presence within cardiothoracic surgery has grown significantly over the past decade. Before 2009 there were 10 or fewer women certified by the ABTS each year. In 2019 , there were 18 women certified by the ABTS. ${ }^{22}$ Within the surveyed group $(n=27)$ many women endorsed never having a female mentor $(44.44 \%)$ or sponsor $(66.67 \%)$ and more than $95 \%$ of responders believed that it would have been helpful for their professional career development to have had a female mentor/sponsor. One responder was even advised against having a female mentor. This responder was told that "women in power are tyrants because they haven't had power for long enough and don't know how to deal with it."

Barriers identified to obtaining a female mentor included the number of women in the department $(61.54 \%)$, personality conflict (11.54\%), time and availability $(7.69 \%)$, and a lack of interest in mentorship (7.69\%). Not only was there a lack of women in the department, many women had never had a female "boss." Only 26\% (7/27) of the women who responded endorsed having a female division chief, program director, or chair. True to many women's experience is the following quote: "I have not had a female mentor so I do not know that it would be helpful or harmful but I think we need women in positions of leadership."

Of the women who did have female mentors and sponsors, many of these mentors were general surgeons or physicians in different fields such as radiology. Now, an overwhelming number of female cardiothoracic surgeons do work with trainees; $20(75.07 \%)$, whereas $7(25.93 \%)$ do not. With more female cardiothoracic surgeons, this is an opportunity for a change in culture and increased female mentorship for upcoming generations. More than $85 \%$ of 
respondents endorsed mentoring another woman ranging from undergraduates, medical students, trainees, and even junior faculty. A responder noted that this ability to mentor upcoming cardiothoracic surgeons is "extremely valuable, and opportunities have shifted dramatically."

One means to break barriers of access to mentors is through social media. Movements such as the \#ILookLikeASurgeon Twitter hashtag and "New Yorker Cover Challenge" are just 2 examples of the profound effect social media. ${ }^{21}$ These movements united female surgeons across the globe and aimed to challenge stereotypes, celebrate differences, and achieve equality in the workplace. ${ }^{23}$ It has portrayed positive and visible female surgical role models to engage and inspire future generations of surgeons. Although not directly providing means of mentorship, it allowed women to build a larger network of same-sex mentor/ mentees who might be remote from where they live and work. Other direct means of mentorship can be achieved through application and acceptance to numerous scholarships that provide access to mentorship. The WTS has numerous scholarships and Williams and colleagues have recently shown how these scholarships lead to successful entry in to the field of cardiothoracic surgery. ${ }^{22}$

\section{SPONSORSHIP/PROMOTION}

Beyond mentoring, sponsorship is also necessary to open doors to leadership roles and significant academic and clinical advancement. Sponsorship entails being an advocate for an individual, opening doors to further success, and leadership. ${ }^{6}$ In our survey, $66.7 \%$ of women $(18 / 27)$ have never had a female sponsor or a woman who has written a letter of recommendation, whereas only $33.33 \%(9 / 27)$ have. Efforts have been made by several organizations toward promotion and sponsorship. Since 1986, the WTS has given various scholarships and grants to women thoracic surgeons and those in training for career development and research funding. The Nina Starr Braunwald

TABLE 1. Demographic characteristics of survey respondents $(\mathbf{N}=27)$

\begin{tabular}{lc}
\hline Characteristic & n $(\%)$ \\
\hline Age, years & \\
$35-37$ & $8(29.6)$ \\
$38-40$ & $12(44.4)$ \\
$41-43$ & $4(14.8)$ \\
$44-46$ & $2(7.4)$ \\
$47-49$ & $0(0)$ \\
$50-52$ & $1(3.7)$ \\
Race & \\
Asian & $9(33.3)$ \\
Black & $1(3.7)$ \\
Caucasian & $15(55.5)$ \\
Hispanic & $2(7.4)$ \\
\hline
\end{tabular}

TABLE 2. Appendix of survey questions

\begin{tabular}{l} 
Survey question (N = 22) \\
\hline What is your surgical subspecialty? \\
What is your practice/training environment? \\
Do you work with trainees? \\
Total number of years in practice? \\
Do you think it would be helpful for your professional/career \\
development to have a female mentor? \\
Have you ever had a female mentor? \\
Have you ever had a female sponsor? \\
Has a female ever written a letter of recommendation for you? \\
Have you experienced any barriers to obtaining a female mentor? \\
Were you ever advised against seeking a female mentor? \\
Have you ever done research with a female? \\
If you have done research with a female, who were these experiences \\
with? \\
If you have done research with a female, was your female colleague \\
typically outside your field? \\
Have you spent time outside of work with a female mentor, ie dinner, \\
If you have done research with a female, who usually initiated the \\
collaboration? \\
Have you ever seen another Thoracic, Cardiac, or Congenital female \\
surgeon operate? \\
Have you seen another female operate in your sub-specialty? \\
Have you ever been invited to give a talk or moderate a session from \\
anothe
\end{tabular}

Fund was established in 1992 to provide career development and research funds for women in cardiac surgery. As of 2017, 27 women have been awarded a total of $\$ 2,215,000$ resulting in 956 confirmed publications. ${ }^{23}$ Additional opportunities for acquiring new technical skills, travel to centers of excellence, and research grants have been supported by important sponsors from industry and represent valuable mechanisms of support.

Formal leadership training courses are another important means by which women can learn important skills for success at every level. Courses often include learning modules on contract negotiation, salary benchmarks, and promotion processes for those in academia. In 2018, The American Association for Thoracic Surgery (AATS) joined with the WTS to expand the highly successful AATS Leadership 
Academy program to a broader audience. The collaboration focused on developing future women leaders by introducing them to the administrative, interpersonal, and mentoring skills necessary to serve in leadership positions in the field of cardiothoracic surgery. ${ }^{15}$ At the 2020 annual meeting of the STS, President Robert Higgins established the inaugural STS Leadership Course with near-equal representation of women and men junior surgeon attendees. Of equal importance was the gender equity among invited speakers and panelists who were highlighted as leaders in our field. ${ }^{6}$ Although progress has been made, there is a dearth of women in higher leadership positions within the STS.

\section{CONCLUSIONS}

Removing all of the barriers to women in surgery will require fundamental and long-lasting social changes in how people perceive the role of women. We cannot deny that women have already made significant strides in representation and accomplishments in the field of thoracic surgery since the first 3 women diplomates were certified by the ABTS. More women have achieved significant positions of leadership, demonstrating that the culture is slowly changing. We recognize that the answer to the lack of diversity and inclusion of women in thoracic surgery is complex and multifaceted. Here, however, we wanted to highlight just one component that we feel could make an impact. Part of the next steps toward achieving a true seat at the table are mentorship and visibility. Watching and learning from the senior women who have succeeded will only help future generations succeed. As we continue to encourage medical students and support young trainees and women who are already in practice, we will join the rising trend that already exists in other specialties. With the voice of women being present more so than ever, we will continue to be part of the change we hope to see.

\section{References}

1. AAMC. Women were majority of U.S. medical school applicants in 2018. Accessed April 9, 2021. https://www.aamc.org/news-insights/press-releases/ women-were-majority-us-medical-school-applicants-2018

2. Association of Women Surgeons. Female chairs of departments of surgery. Accessed April 9, 2021. https://www.womensurgeons.org/page/FemaleSurgery Chairs

3. AAMC. The state of women in academic medicine. Accessed April 9, 2021. https://www.aamc.org/data-reports/faculty-institutions/report/state-women-acad emic-medicine
4. Antonoff MB, David EA, Donington JS, Colson YL, Litle VR, Lawton JS, et al. Women in thoracic surgery: 30 years of history. Ann Thorac Surg. 2016;101: 399-409. https://doi.org/10.1016/j.athoracsur.2015.11.014

5. Incorvaia AN, Ringley CD, Boysen DA. Factors influencing surgical career decisions. Curr Surg. 2005;62:429-35. https://doi.org/10.1016/j.cursur.2005.02.002

6. Preventza O, Backhus L. US women in thoracic surgery: reflections on the past and opportunities for the future. J Thorac Dis. 2021;13:473-9. https: //doi.org/10.21037/jtd.2020.04.13

7. Donington JS, Litle VR, Sesti J, Colson YL. The WTS report on the current status of women in cardiothoracic surgery. Ann Thorac Surg. 2012;94:452-9. https: //doi.org/10.1016/j.athoracsur.2012.03.102

8. Neuhaus SJ. Surgery: no profession for a lady. ANZ J Surg. 2016;86:34-8. https: //doi.org/10.1111/ans.13369

9. Benfield JR, Kohman LJ. Mentorship, women thoracic surgeons, and the thoracic surgery foundation for research and education. Ann Thorac Surg. 2004;78: 1135-6. https://doi.org/10.1016/j.athoracsur.2004.06.028

10. Women in Thoracic Surgery. Mission statement and goals. Accessed April 9, 2021. https://wtsnet.org/about/mission/

11. Mission of the Women in Thoracic Surgery. Accessed November 28, 2021 https://wtsnet.org/content/uploads/2021/04/WTS-History_2010_Rev-Feb-2014. pdf

12. Dresler CM, Padgett DL, MacKinnon SE, Patterson GA. Experiences of women in cardiothoracic surgery. A gender comparison. Arch Surg. 1996; 131:1128-34; discussion: 1135. https://doi.org/10.1001/archsurg.1996.01430 230010002

13. Edwards BM, Gillaspie E. The Queen of Lung Cancer Surgery : Carolyn E Reed. Accessed November 28, 2021. https://www.wtsnet.org/content/uploads/2021/04/ Carolyn-Reed-for-WTS-Website.pdf

14. Crawford FA. Carolyn Elaine Reed, MD March 4, 1950-November 16, 2012 Ann Thorac Surg. 2013;96:1517-9. https://doi.org/10.1016/j.athoracsur.2013. 07.107

15. Mahoney ST, Strassle PD, Schroen AT, Agans RP, Turner PL, Meyer AA, et al. Survey of the US surgeon workforce: practice characteristics, job satisfaction, and reasons for leaving surgery. J Am Coll Surg. 2020;230:283-93.e1. https: //doi.org/10.1016/j.jamcollsurg.2019.12.003

16. NEJM CareerCenter. Women physicians in the specialties: making gains. Accessed April 9, 2021. https://www.nejmcareercenter.org/article/womenphysicians-in-the-specialties-making-gains/

17. Ahmadiyeh N, Cho NL, Kellogg KC, Lipsitz SR, Moore FD Jr, Ashley SW, et al Career satisfaction of women in surgery: perceptions, factors, and strategies. $J$ Am Coll Surg. 2010;210:23-8. https://doi.org/10.1016/j.jamcollsurg.2009.08. 011

18. Wirtzfeld DA. The history of women in surgery. Can J Surg. 2009;52:317-20. https://doi.org/10.1016/S0008-428X(09)50102-6

19. Inzer L. A review of formal and informal mentoring: processes, problems, and design. J Leadersh Education. 2005;4:31-50. https://doi.org/10.12806/V4/I1/ TF2

20. Neumayer L, Kaiser S, Anderson K, Barney L, Curet M, Jacobs D, et al. Perceptions of women medical students and their influence on career choice. Am J Surg. 2002;183:146-50. https://doi.org/10.1016/S0002-9610(01)00863-7

21. Luc JGY, Stamp NL, Antonoff MB. Social media in the mentorship and networking of physicians: important role for women in surgical specialties. $\mathrm{Am}$ J Surg. 2018;215:752-60. https://doi.org/10.1016/j.amjsurg.2018.02.011

22. Williams KM, Hironaka CE, Wang H, Bajaj SS, O’Donnell CT, Sanchez M, et al. Women in Thoracic Surgery Scholarship: impact on career path and interest in cardiothoracic surgery. Ann Thorac Surg. 2021;112:302-7. https://doi.org/10. 1016/j.athoracsur.2020.07.020

23. Blackmon SH, Carpenter AJ. Nina Starr Braunwald's career, legacy, and awards results of a survey of the Thoracic Surgery Foundation Award recipients. Ann Thorac Surg. 2018;106:633-6. https://doi.org/10.1016/j.athoracsur.2018.02.033 